\title{
Postoperative mental disorder following prolonged oral surgery
}

\author{
Teruhito Kunimatsu ${ }^{\S, \dagger}$, Toru Misaki ${ }^{\S, \dagger}$, Noriya Hirose ${ }^{\S, \dagger}$, Eitatsu Tsuboi ${ }^{\S, \dagger}$, \\ Ichiro Takahashi $^{\S}$, Hidero Ohki ${ }^{\mathbb{I l},}$, Yoshiyuki Oi ${ }^{\S, \dagger}$, Mitsuhiko Matsumoto ${ }^{\mathbb{I l} \dagger}$ \\ and Hiroshi Tanaka ${ }^{\mathrm{II}} \dagger$
}

\begin{abstract}
Departments of ${ }^{\S}$ Dental Anesthesiology and II Oral and Maxillofacial Surgery, Nihon University School of Dentistry, Tokyo, Japan

Divisions of ${ }^{\dagger}$ Immunology and Pathology, and ${ }^{\ddagger}$ Systemic Biology and Oncology, Dental Research Center, Nihon University School of Dentistry, Tokyo, Japan
\end{abstract}

(Received 4 November 2003 and accepted 28 January 2004)

\begin{abstract}
A prolonged period of oral surgery is a potential risk factor of postoperative mental disorders although no such report has been published to date. We retrospectively studied perioperative features in 36 patients who underwent prolonged ( 10 hours or more) of oral surgery. Patients were categorized as predelirium (Pre-D) when they manifested 1 or 2 symptoms and delirium (D) when they showed more than 2 symptoms, according to the modified International Classification of Diseases, 10th edition. Of the 36 patients who returned to a normal mental state without drug therapy, 13 were classified as D and 14 were PreD. A number of patients had moderate complications preoperatively, and massive hemorrhaging occurred during the operation in some Pre-D and D patients. Age was greater in $D(62.0 \pm 9.9$ years $)$ than in Pre-D (56.0 \pm 13.8 years) patients. Propofol-based general anesthesia was most commonly employed. The time prior to appearance of pre-delirium was significantly shorter in D (30.0 \pm 16.7 hours) than in Pre-D (55.0 \pm 35.0 hours) group patients. Our results indicate that, in general, patients predisposed to postoperative mental disorders have moderate complications preoperatively, are generally older than 50-years-old, receive propofolbased general anesthesia and/or experience a massive
\end{abstract}

Correspondence to Dr. Teruhito Kunimatsu, Department of Dental Anesthesiology, Nihon University School of Dentistry, 1-8-13 Kanda-Surugadai, Chiyoda-ku, Tokyo 101-8310, Japan Tel: +81-3-3219-8140

Fax: +81-3-3219-8357

E-mail: kunimatsu@dent.nihon-u.ac.jp hemorrhage during the operation. (J. Oral Sci. 46, 7174, 2004)

Key words: prolonged oral surgery; postoperative delirium; perioperarive management.

\section{Introduction}

In recent years, reconstructive oral surgery procedures following malignant tumor excision have advanced, and are now routinely performed to improve oral function and esthetics. When tumor excision is performed with reconstructive surgery on the same day, a longer operative period and more complicated perioperative management are required. Postoperative management can adversely affect the patient's mental state through forced bed rest, an inability to communicate, and unexpected facial changes. This can result in mental disorders including a postoperative delirium. The incidence of postoperative delirium following oral surgery (all types) has been found to be higher than that following orthopedic or otolaryngologic surgery, and approximately equivalent to that following neurosurgery (1). To our knowledge, however, there is no published data on signs of and risk factors for postoperative mental disorder development following prolonged oral surgery. In the present study, we retrospectively studied the characteristics of patients who showed postoperative mental disorder symptoms following prolonged oral surgery (10 hours or more) in order to help establish effective preventive protocols in future. 


\section{Materials and Methods}

Thirty-six patients who had undergone an operation for more than 10 hours to excise a malignant tumor and for reconstructive surgery of the oral cavity at Nihon University Dental Hospital at Surugadai between 1998 and 2002 were included in this study. The physical status (PS) of each patient was assessed preoperatively according to the American Society of Anesthesiology (ASA) criteria as PS 1 (normal physical status excluding operative diagnosis), PS 2 (moderate complications), or PS 3 (severe complications). The characteristics of the patients and the operative methods, including diagnosis, surgical reconstruction technique, duration of anesthesia, duration of operation and intraoperative complications, were also assessed. Postoperative delirium was determined from nursing $\log$, according to the diagnostic symptoms described in the International Classification of Diseases, 10th edition (ICD-10; Table 1) (2), with some modification. The importance of each symptom (including its timing) for the development of postoperative delirium is not considered in ICD-10, yet based on our previous experience, we hypothesized that pre-delirium (Pre-D), often seen before a state of delirium and indicated by a minimum of 1 symptom from ICD-10, is a crucial marker of risk of delirium. Therefore, we categorized patients as Pre-D,

Table 1 Criteria for postoperative delirium

Disturbance of:
Consciousness and attention
Perception
Thinking
Memory
Psychomotor behaviour
Emotion
Sleep-wake cycle

indicated by a minimum of 1 symptom (Group Pre-D), or delirium, indicated by the presence of more than 2 symptoms (Group D). Patients without ICD-10 symptoms were categorized as no delirium (Group ND).

Statistical analysis

The Student's $t$-test was used for comparisons between the ND and Pre-D, ND and D, and Pre-D and D groups. All values are presented as mean \pm S.D., with $P<0.05$ considered statistically significant.

\section{Results}

Twenty-seven $(75 \%)$ of the 36 cases were considered Pre-D or D and then returned to a normal mental state without drug therapy. Of these 27, $13(36.1 \%)$ showed a transition from Pre-D to D, and 14 (38.9\%) showed Pre$\mathrm{D}$ only. Based on these results, the patients were divided into the 3 groups ND, Pre-D, and D (Table 2).

For pre-anesthetic medication, atropine and pethidine were given to all patients. Males were more likely to be in the Pre-D or D group. Mean age was significantly higher in the $\mathrm{D}(62.0 \pm 9.9$ years $)$ than in the ND $(56.0 \pm$ 13.8 years) group. The majority of patients in groups Pre$\mathrm{D}$ and $\mathrm{D}$ had moderate complications preoperatively.

Squamous cell carcinoma (SCC) of the tongue was the most common presenting diagnosis in group Pre-D, while SCC of the floor of the mouth was most common in group D. Gingival SCC was the second most common diagnosis in both the Pre-D and D groups.

A forearm flap was the most frequently employed reconstructive method in all 3 groups. Tumor excision and uni- or bilateral upper/total neck dissection were employed in all patients. For general anesthesia, modified neuroleptanesthesia (m-NLA) was the most commonly employed in all 3 groups. No significant differences in duration of anesthesia or surgery were observed between groups. A number of patients in the Pre-D and D groups

Table 2 Clinical profiles

\begin{tabular}{|c|c|c|c|c|c|c|c|c|c|c|c|c|}
\hline Group & Gender & Age (yr) & ASA PS & Diagnosis & Reconstruction & Anesthesia & Duration of & Duration of & Intraoperative & The time prior to & he appearance & The period of \\
\hline $\begin{array}{l}\mathrm{ND} \\
(\mathrm{n}=9)\end{array}$ & $\begin{array}{l}\text { Male: } 6 \\
\text { Female: } 3\end{array}$ & $52 \pm 15.6$ & $\begin{array}{l}\text { PS } 1: 6 \\
\text { PS } 2: 3\end{array}$ & $\begin{array}{l}\text { Tongue SCC: } 3 \\
\text { MB-SCC: } 2 \\
\text { G-SCC: } 2 \\
\text { OS: } 1 \\
\text { SCC-FM: } 1\end{array}$ & $\begin{array}{l}\text { FA flap: } 8 \\
\text { Tongue flap: } 1\end{array}$ & m-NLA: 9 & $1034 \pm 167.1$ & $971 \pm 168.9$ & Massive hemorrhage: 1 & pre-delirium (hrs) & delirium (hrs) & \\
\hline $\begin{array}{c}\text { PD } \\
(\mathrm{n}=14)\end{array}$ & $\begin{array}{l}\text { Male: } 11 \\
\text { Female: } 3\end{array}$ & $56 \pm 13.8$ & $\begin{array}{l}\text { PS 1: } 1 \\
\text { PS 2: } 13\end{array}$ & $\begin{array}{l}\text { Tongue SCC: } 8 \\
\text { G-SCC: } 5 \\
\text { SCC-FM: } 1\end{array}$ & $\begin{array}{c}\text { FA flap: } 10 \\
\text { FA flap + MRTP: } 2 \\
\text { D-P: } 1\end{array}$ & $\begin{array}{c}\text { m-NLA: } 12 \\
\text { GOS: } 1 \\
\text { TIVA: } 1\end{array}$ & $1002 \pm 203.2$ & $918 \pm 204.5$ & $\begin{array}{c}\text { Massive hemorrhage: } 9 \\
\text { Arrythmia: } 1\end{array}$ & $55.0 \pm 35.0$ & & $30.0 \pm 13.5$ \\
\hline $\begin{array}{c}\mathrm{D} \\
(\mathrm{n}=13)\end{array}$ & $\begin{array}{l}\text { Male: } 11 \\
\text { Female: } 2\end{array}$ & $62 \pm 9.9^{*}$ & $\begin{array}{l}\text { PS 1: } 1 \\
\text { PS 2: } 12\end{array}$ & $\begin{array}{l}\text { SCC-FM: } 6 \\
\text { Tongue SCC: } 2 \\
\text { G-SCC: } 5\end{array}$ & $\begin{array}{c}\text { FA flap: } 10 \\
\text { PMMC flap: } 1 \\
\text { IB graft: } 1 \\
\text { FA flap + IB graft: } 1\end{array}$ & $\begin{array}{c}\text { m-NLA: } 9 \\
\text { o-NLA: } 2 \\
\text { GOS: } 1 \\
\text { TIVA: } 1\end{array}$ & $1072 \pm 196.4$ & $1008 \pm 198.2$ & $\begin{array}{c}\text { Massive hemorrhage: } 10 \\
\text { Arrythmia: } 2\end{array}$ & $30.0 \pm 16.7 * *$ & $83.0 \pm 28.2$ & $102 \pm 46.6$ \\
\hline
\end{tabular}

ASA PS: Evaluation of Physical Status according to American Society of Anesthesiology criteria; GOS: General anesthesia using inhaled nitrous oxide, oxygen and sevoflurane; m-NLA: Modified method of neuroleptanesthesia using nitrous oxide, oxygen, fentanyl and propofol; o-NLA: Original method of neuroleptanesthesia using nitrous oxide, oxygen, fentanyl and droperidol; TIVA: Total intravenous anesthesia using air, oxygen, fentanyl and propofol; DP flap: Delto-pectoral flap; FA flap: Forearm flap; IB graft: Iliac-bone graft; MRTP: Mandibular reconstruction using titanium plate; PMMC flap: Pectoralis major myocutaneous flap; G-SCC: Gingival squamous cell carcinoma; MB-SCC: Mucobuccal squamous cell carcinoma; OS: Osteosarcoma; SCC-FM: Squamous cell carcinoma of floor of the mouth; Tongue SCC: Squamous cell carcinoma of the tongue; Massive hemorrhage: Hemorrhage $>1200 \mathrm{~g}$

$* P<0.05$ vs. Group None-D, ** $P<0.05$ vs. Group Pre-D 
developed massive hemorrhaging during the operation. The time period prior to Pre-D was significantly shorter in group $\mathrm{D}$ than Pre-D. The duration of symptoms following the appearance of Pre-D and D was $30.0 \pm 13.5$ hours and $102.0 \pm 46.9$ hours, respectively.

\section{Discussion}

The incidence of postoperative delirium with all surgical method has previously been reported to be $36.8 \%$ (3). In the present study, if only the D group was considered, the incidence of delirium (36.1\%) was quite similar to these previous results. However, our results showed that mental disorders (both pre-delirium and delirium) were apparent in $75 \%$ of the patients who underwent more than 10 hours of oral surgery. In general, only symptomatic treatment has been provided for postoperative mental disorders, while prophylaxis treatment has been limited. The results of the present study suggest that it is important to identify signs of postoperative delirium in order to provide effective postoperative management following prolonged oral surgery.

It has been reported that the postoperative environment is the most crucial factor in the development of postoperative mental disorders $(4,5)$. For example, in most cases of prolonged oral surgery, a tracheotomy for intraand postoperative respiratory management is required and this challenges the ease of communication between the patients and their family, and the doctors and nurses immediately following surgery. In addition, forced bed rest may be required for several days after reconstructive surgery and this, again, can be challenging. In line with this, the incidence of postoperative delirium is reportedly high following surgery for hip fracture, as patients generally require several days of postoperative forced bed rest (6). Additional mental stress may result from unexpected facial changes.

It has previously been reported that the incidence of postoperative delirium is higher in patients over 75 -yearsold $(3,6,7)$, although in the present study the $\mathrm{D}$ group was significantly younger $(62.0 \pm 9.9$ years $)$. Other factors that have been implicated in the development of postoperative mental disorder include gender $(1,3,4,6,8)$, preoperative physical state $(1,3,4,8,9)$, physiological changes during the operation $(9,10-14)$ and the use of general anesthetics (1). More specifically, it has been reported that the incidence of postoperative mental disorder is higher in men than women (1). Since 28 of the 36 patients in the present study were men, no definitive conclusions can be made here. However, our experiences with postoperative management suggest that women tend to handle postoperative psychological stress better than men.
The majority of patients in the Pre-D and D groups had moderate complications preoperatively, and this was predominantly cerebrovascular disease assessed at the PS 2 level (Table 2). The incidence of postoperative mental disorder has been reported to be higher in patients with moderate or severe cerebrovascular disease (1). Further, preoperative complications, particularly cerebrovascular disease, may increase the risk of intraoperative cerebral ischemia and thus result in mental disorders following prolonged surgery (15).

Massive hemorrhaging during the operation reportedly reduces cerebral oxygen supply, a condition similar to cerebral ischemia, and may play a role in postoperative mental disorders $(1,9)$. A number of the patients in both the Pre-D and D groups had a massive hemorrhage during the operation (Table 2).

With regards to general anesthesia, no marked differences have been reported in the incidence of postoperative mental disorder between various volatile inhaled anesthetics (8). However, with intravenous anesthetics, the incidence of postoperative mental disorder has been reported to be significantly higher in the case of propofol-based than in sevoflurane-based anesthesia (1). In the present study, mNLA using propofol was most commonly employed, which suggests that prolonged propofol-based general anesthesia may have an effect on the central nerve system.

The time prior to the appearance of mental disorders was significantly shorter in group D than Pre-D (Table 2). This suggests that patients who have a possibility of developing postoperative delirium show initial signs, such as a reversed sleep-wake cycle in the early postoperative period. In addition, once postoperative delirium appeared, the symptoms lasted for approximately 4 days, even with palliative treatment. Therefore, we consider the first 30 hours after the postoperative period as the most crucial in which to limit Pre-D or the transition to complete delirium, and preventative measures (altering environmental conditions, adding drug therapy) must be actively employed at that stage.

Once postoperative delirium occurs, altering of the environmental conditions and/or drug therapy is recommended (Table 3) $(3,5,16)$. Environmental improvement includes placing the patient in a quiet and darkened room, and reversing sleep-wake cycle $(5,9)$. In our facility, we have attempted to improve environmental conditions by undertaking postoperative management in private rooms with restricted visits. This is performed in order to limit postoperative infection and protect patient privacy because of facial disfigurement following major oral surgery.

In terms of drug therapy, initial postoperative pain 
Table 3 Management for postoperative delirium

\begin{tabular}{cl}
\hline Primary & Environmental support: \\
Well-lit, cheerful room \\
Quiet surroundings \\
Keep patient oriented \\
Visits by friends or family \\
Adequate analgesia \\
Secondary (after/concurrent with primary Rx) \\
Pharmacotherapy: \\
Haloperidol \\
Droperidol \\
Chlorpromazine \\
Diazepam
\end{tabular}

management is paramount (16), followed by administration of haloperidol, droperidol, or benzodiazepine for symptomatic treatment $(3,4,6,8)$. In the present study, fentanyl, benzodiazepine and/or propofol were generally used for symptomatic treatment. However, repeatable favorable effects were not obtained, suggesting that symptomatic treatment is not effective after postoperative delirium has developed. In our facility, we have given preventive haloperidol combined with benzodiazepine to obtain a stable sleep-awake cycle within 24 hours of the postoperative period in a number of patients who had undergone prolonged oral surgery and satisfactory results were reported by nurses, doctors, and patients in regards to postoperative mental management (unpublished data). While prophylactic drug therapy may be effective for prevention of postoperative delirium following prolonged oral surgery, additional and larger studies are needed to confirm these initial findings.

\section{References}

1. Furuya H, Nakahashi K, Hirai K, Yoshikawa M, Kitaguchi K, Morooka T, Horiuchi T, Kurita N, Iwatsubo T, Shimoda T (2001) Assessment of anesthesia satisfaction using direct interviews at post-anesthesia clinic. Masui 50, 240-245 (in Japanese)

2. World Health Organization (1992) V Mental and behavioural disorders, The ICD-10; International statistical classification of diseases and related health problems, tenth revision, WHO, Geneva, 318

3. Dyer CB, Ashton CM, Teasdale TA (1995) Postoperative delirium. A review of 80 primary data-collection studies. Arch Intern Med 155, 461465

4. O’Keeffe ST, Ni Chonchubhair A (1994) Postoperative delirium in the elderly. Br J Anaesth $73,673-687$
5. Tsutsui S, Kitamura M, Higashi H, Matsuura H, Hirashima S (1996) Development of postoperative delirium in relation to a room change in the general surgical unit. Surg Today 26, 292-294

6. Parikh SS, Chung F (1995) Postoperative delirium in the elderly. Anesth Analg 80, 1223-1232

7. Francis J, Martin D, Kapoor WN (1990) A prospective study of delirium in hospitalized elderly. JAMA 263, 1097-1101

8. Moller JT, Cluitmans P, Rasmussen LS, Houx P, Rasmussen H, Canet J, Rabbitt P, Jolles J, Larsen $\mathrm{K}$, Hanning CD, Langeron O, Johnson T, Lauven PM, Kristensen PA, Biedler A, van Beem H, Fraidakis O, Silverstein JH, Beneken,JE, Gravenstein JS (1998) Long-term postoperative cognitive dysfunction in the elderly ISPOCD1 study. ISPOCD investigators. International Study of Post-Operative Cognitive Dysfunction. Lancet 351, 857-861

9. van der Mast RC, Fekkes D, Moleman P, Pepplinkhuizen L (1991) Is postoperative delirium related to reduced plasma tryptophan? Lancet 338, 851-852

10. Blass JP, Plum F (1983) Metabolic encephalopathies in older adults. In The Neurology of Aging. Katzman R, Terry R eds, Davis FA, Philadelphia, 189-220

11. Hirsch JA, Gibson GE (1984) Selective alteration of neurotransmitter release by low oxygen in vitro. Neurochem Res 9, 1039-1049

12. McIntosh TK, Bush HL, Yeston NS, Grasberger R, Palter M, Aun F, Egdahl RH (1985) Beta-endorphin, cortisol and postoperative delirium: a preliminary report. Psychoneuroendocrinology 10, 303-313

13. Marcantonio ER, Juarez G, Goldman L, Mangione CM, Ludwig LE, Lind L, Katz N, Cook EF, Orav EJ, Lee TH (1994) The relationship of postoperative delirium with psychoactive medications. JAMA 272, 1518-1522

14. Chen X, Zhao M, White PF, Li S, Tang J, Wender RH, Sloninsky A, Naruse R, Kariger R, Webb T, Norel E (2001) The recovery of cognitive function after general anesthesia in elderly patients: a comparison of desflurane and sevoflurane. Anesth Analg 93, 1489-1494

15. Saeki S, Watanabe N, Iida R, Kashiwazaki M, Itoh S, Ogawa S, Suzuki H (1998) A study of postoperative delirium in elderly patients. Masui 47, 290-299 (in Japanese)

16. Lynch EP, Lazor MA, Gellis JE, Orav J, Goldman L, Marcantonio ER (1998) The impact of postoperative pain on the development of postoperative delirium. Anesth Analg 86, 781-785 